\title{
Um mar de problemas: interesses estratégicos e a luta pelo poder no Mar do Sul da China
}

\author{
A sea of troubles: strategic interests \\ and the struggle for power in the South China Sea
}

Rev. Bra. Est. Def. v. 4, nº 1, jan./jun. 2017, p. 181-201

\section{WAGNER SANTOS}

\section{INTRODUÇÃO}

A ascensão da China como um ator-chave no cenário global é, sem dúvida, um fenômeno de grande impacto nas relações internacionais (Shambaugh 2005; Talmon; Jia 2014; Wang 2004). Muito se tem debatido sobre como seu crescente poder econômico, político e militar tem sido usado para que seus interesses, nacionais e internacionais, sejam alcançados, e como o mundo deve responder a uma China cada vez mais poderosa e decisiva, local e mundialmente. Para Li (2009), embora importantes, essas questões não podem ser totalmente respondidas sem que sejam consideradas as percepções de segurança chinesas que têm levado o país a tomar decisões cada vez mais expansionistas. Como os líderes chineses e as elites políticas do país compreendem a estrutura do sistema internacional do pós-Guerra Fria? Como eles percebem os interesses da China e seu papel em um contexto de segurança internacional cada vez mais dinâmico? E como essas questões se relacionam com a política doméstica e a agenda econômica do país?

Wagner Santos - Doutorando em Ciência Política pela Universidade Federal de Pernambuco. 


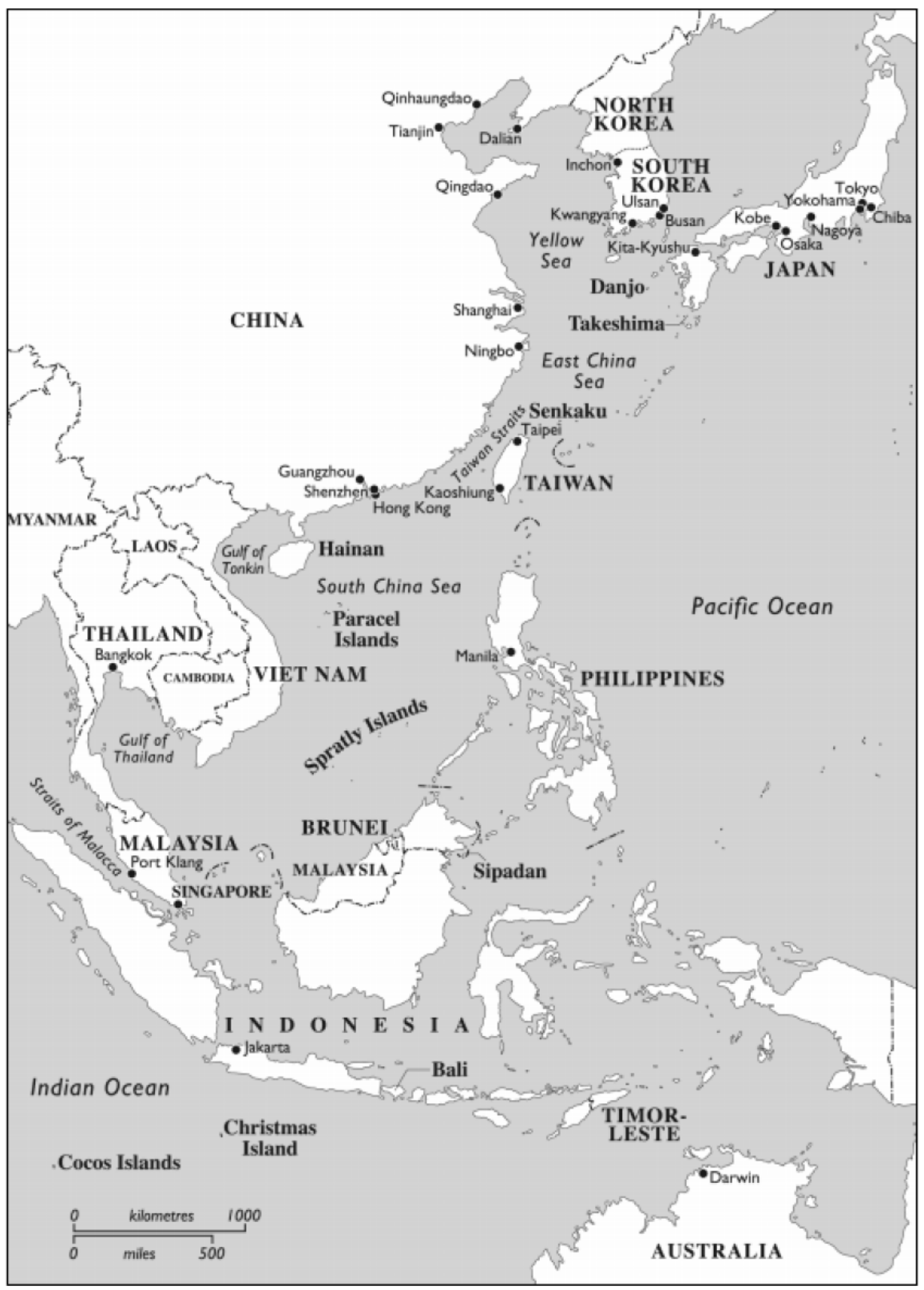

Mapa 1 - O Mar do Sul da China

Fonte: Cáceres (2014, xii). 
Esta pesquisa, considerando tais desafios, analisa as disputas territoriais cada vez mais acirradas e perigosas na região do Mar do Sul da China (MSC), com impactos sobre todos os países localizados em seu entorno e que tem alertado os Estados Unidos sobre a crescente influência chinesa na área. Desde o estabelecimento da República Popular da China (RPC), os líderes chineses têm dado extrema importância política às questões de segurança e cálculos estratégicos (Lo 1989). Mais recentemente, sobretudo a partir da década de 1990, a China tem buscado manter parcerias estratégicas com grandes atores internacionais. Não há dúvidas que o gigante asiático possui aspirações globais. Todavia, por questões históricas e geográficas, o Sul e o Leste Asiático permanecem sendo seus focos principais (Buszynski; Roberts 2014; Li 2009).

Em termos de desenvolvimento econômico e questão de segurança, o Sul e o Leste Asiático são considerados pelos líderes chineses como fundamentais. São áreas em que as atividades comerciais e econômicas chinesas dependem; onde a China possui interesses de segurança vitais, ao passo que disputas territoriais mal resolvidas podem facilmente conduzir a um conflito militar. Por isso, não é surpresa que seus líderes prestem cada vez mais atenção aos movimentos das grandes potências na região (Thuy; Trang 2015). Especial atenção tem sido dada à Rússia e aos Estados Unidos, potências nucleares e membros permanentes do Conselho de Segurança das Nações Unidas (CSNU). Mas também ao Japão, que embora possua limitada capacidade militar, é uma potência econômica com perfil global em expansão.

Apesar de uma série de acordos terem sido firmados no início de 1960, as disputas sobre muitas partes das fronteiras chinesas permanecem instáveis. Segundo Lo (1989), desde 1949 a China reivindicou territórios com praticamente todos os seus vizinhos que são banhados pelo MSC. A disputa territorial chinesa com eles tem sido acompanhada por grandes operações militares que comprometem a estabilidade regional: a disputa ao longo da fronteira sino-indiana em 1962; a fronteira sino-soviética em 1969 e a disputa sobre as Ilhas Paracel em 1974 são alguns exemplos (Weissmann 2010).

Como consequência de um ambiente historicamente tenso, as disputas territoriais no MSC têm se tornado um campo fértil e uma importante área de investigação para a política externa chinesa. Não é diferente nesta pesquisa: o que está em jogo nas disputas territoriais no Mar do Sul da China? Por que ela é tão estratégica para a China e seu ímpeto expansionista? Qual a importância comercial da região para a economia chinesa? Por que a China tem realizado operações militares com frequência para fazer valer suas reivindicações territoriais? Qual o impacto dessas operações 
para o equilíbrio regional? Por que os Estados Unidos possuem interesse na região? Pode a China entrar em conflito com os Estados Unidos pelo controle local? Tais questionamentos são cruciais para se entender o atual contexto de disputa territorial no MSC e serão analisados ao longo desta pesquisa.

Este artigo gira em torno de pelo menos três tópicos centrais: no primeiro, início expondo a posição geográfica do Mar do Sul da China e suas riquezas natural e mineral, revelando a importância econômica da região, sobretudo para a indústria pesqueira, e, posteriormente, analiso sua relevância geoestratégica como central para as disputas territoriais na região. No segundo, elenco os principais países e suas reivindicações de soberania. Nesta parte, que não será exaustiva, sintetizo os principais argumentos e o que está em jogo em cada reivindicação. No terceiro, levanto uma temática cada vez mais debatida: a possibilidade do conflito entre a China e os Estados Unidos pelo controle da região. Ao final, exponho as dificuldades de se analisar a questão das disputas territoriais, uma vez que envolvem desde questões culturais e históricas, até argumentos geopolíticos e estratégicos em defesa da segurança regional e contra possíveis ataques militares ao continente Asiático.

\section{O MAR DO SUL DA CHINA}

\section{Posição geográfica e riquezas natural e mineral}

O Mar do Sul da China compreende uma região semifechada localizada ao Sul da China Continental e Taiwan, limitada a Leste pelas Filipinas, a Oeste por Taiwan, e ao Sul por Brunei e Malásia (ver Mapa 1). Considerado o maior mar do mundo, e cobrindo uma área de aproximadamente 3,5 milhões de $\mathrm{km}^{2}$, possui um grande número de ilhas, das quais a maioria é desabitada. Dentre as mais importantes estão as Ilhas Paracel e Spratly. As reivindicações da China, Vietnã, Filipinas, Malásia, Brunei e Taiwan sobre esses grupos de ilhas e rochas, que foram ocupados por vários países requerentes de soberania sobre eles, tem sido uma fonte contínua de tensão que, por sua vez, mina a paz e a estabilidade em toda região Ásia-Pacífico (Bateman; Emmers 2009; Talmon; Jia 2014).

O MSC se conecta com outros mares através de três estreitos: Taiwan, Lombok e Malacca, onde faz o encontro estratégico entre os Oceanos Pacífico e Índico. Em toda sua extensão, o MSC tem aproximadamente 2000 quilômetros no sentido Norte-Sul e 1000 quilômetros no Leste-Oeste. Possui um grande número de ilhas, recifes e rochas distribuídas por toda sua extensão (Hong 2012). 
Por sua grande dimensão e localização privilegiada, a área detém riquezas naturais e minerais que têm despertado a cobiça dos países asiáticos, mas também de outras potências, em especial pelo fato de um terço dos seus quase 3 milhões de $\mathrm{km}^{2}$ estar localizado sobre uma plataforma continental de menos de 200 metros de profundidade, sobretudo a Oeste e Sul da Ásia (Djalal 1998). Embora não seja difícil precisar a profundidade de plataformas continentais, a presença de petróleo e gás é. A estimativa do potencial de recursos minerais varia bastante. Bateman (2009) ressalta que, enquanto os Estados Unidos alegam ser a área detentora de 7 bilhões de barris de óleo, o governo chinês estima o potencial entre 105-213 bilhões de barris. O mesmo se aplica ao potencial de hidrocarbonetos, gás e petróleo, ao passo que as estimativas são divergentes e incertas. Enquanto a Agência de Energia Americana ${ }^{1}$ estima que existam reservas de 11 bilhões de barris de petróleo e aproximadamente 190 trilhões de metros cúbicos de gás, as autoridades chinesas consideram 125 bilhões de barris de petróleo e 500 trilhões de metros cúbicos de gás, respectivamente. Todavia, independente da divergência, muitas vezes não por acaso, nesses dados, eles revelam a riqueza e importância da área como fonte de recursos essenciais para o mercado internacional.

Além da notória riqueza mineral e potencial de reservas de óleo e gás, o MSC é uma das regiões marinhas mais importantes do mundo, com centenas de variedades de peixes, a ponto de ocupar a quarta posição mundial em áreas mais ricas de espécies de peixes (Næss, 2002). Sua capacidade pesqueira é estimada em 7,5 toneladas por $\mathrm{km}^{2}$ anuais, apenas ao redor das Ilhas Spratly. Anualmente, os Estados do Mar do Sul da China produzem mais de 8 milhões de toneladas de peixes, respondendo por $1 / 10(10 \%)$ de toda a captura mundial e $23 \%$ de todo continente asiático, tornando-se vital para as indústrias de pesca dos países da região (Dupont 1998; Xinjun 2015). Bateman (2009) ainda ressalta que cento e vinte e cinco grandes rios desaguam em diversos pontos do MSC, e mais de 30 por cento de todos os corais do mundo estão, ou fazem fronteira, ao longo da região, em especial ao redor dos arquipélagos da Indonésia e Filipinas.

Por sua riqueza natural e mineral, a região tornou-se uma das rotas marítimas de maior circulação no mundo, passando por suas águas mais da metade da frota perolífera e comercial do mundo. Rosenberg (2010) explica que toda essa movimentação corre devido à localização geográfica, sendo o caminho mais curto a partir do Oriente Médio e da África para o escoamento de petróleo e recursos naturais rumo à Ásia, além de dar estratégico acesso ao Sudeste Asiático, onde encontra os maiores exportadores de produtos manufaturados do mundo. 


\section{Interesse geopolítico}

A vasta maioria das ilhas presentes no MSC, em especial as Ilhas Spratly, são remotas, improdutivas, áridas, pequenas, desabitadas, rochosas, de baixa elevação e próximas ao nível do mar. Mesmo as partes maiores e com algum potencial de habitação não têm sido capazes de manter uma população constante e com condições essenciais de vida, limitando-se a serem pontos de pesca rotineiros. A ausência de habitação permanente pode ser atribuída às características físicas das ilhas, tanto pelo tamanho quanto pela inexistência de água doce. Até mesmo a vegetação não consegue ser significativa, tornando o local pouco atraente nessas questões (Schofield 2009). Além disso, a única fonte real de riqueza é a pesca. A presença de grandes porções de hidrocarbonetos, óleo e gás natural, embora relevantes, permanecem sendo estimativas. E mesmo se as estimativas forem verdade, ainda se faz necessário o desenvolvimento de técnicas de perfuração para exploração desses recursos. Dito isto, o benefício econômico não pode ser a única atração que o Mar do Sul da China pode trazer aos países que o reivindicam. Nesses termos, questiona-se: por que a região tem sido alvo de cobiça e disputas históricas entre os países banhados pelo Mar? A resposta está em sua posição geoestratégica (Anh 2015; Kim 2015; Thuy; Trang 2015).

É a importância geoestratégica que tem sido a principal razão para as partes envolvidas disputarem e reivindicarem as Ilhas Spratly e Paracel. Como oceano que conecta todos os territórios litorâneos do Sul e Sudeste Asiático, o MSC tem sido usado há séculos pela sua localização estratégica. Anh (2015) ressalta que o Mar do Sul da China é a porta de entrada e saída do mundo para os países do Sul Asiático, sendo também o elo para a navegação e uma importante barreira natural de segurança para vários países litorâneos. Uma vez que questões acerca da segurança marítima e liberdade de navegação em tempos de pirataria têm sido cada vez mais frequentes, e não são apenas de interesse de países costeiros, mas de todos que utilizam o mar com alguma finalidade, o MSC pode ser classificado geopolítica, econômica e estrategicamente como um dos mares mais importantes do mundo (Bateman 2009; Hayton 2014; Jun 2015).

O Mar do Sul da China fornece um vasto oceano de acesso para os países da região. Mesmo sendo o terceiro maior país do mundo em dimensão territorial, a China possui uma desvantagem estratégica em espaço marítimo. É porta de saída do país para o mundo. Torna-se compreensível o desejo expansionista chinês pelas ilhas, não apenas para expandir seu espaço marítimo, mas também servir como rota estratégica para suas constantes ações militares. Por sua vez, a mesma importância tem para 
os demais Estados ao seu redor, sendo um bem comum que naturalmente gera tensão e incerteza sobre possíveis movimentos militares que possam colocar em cheque a estabilidade regional, uma vez que todos desejam desfrutar da riqueza e prosperidade que a região pode trazer (Cáceres 2014; Swaine 1998).

Também é uma rota estratégica de abastecimento para a maioria das economias da região, fornecendo, em suas rotas, segurança vital para muitos países. Sendo um dos maiores importadores de petróleo e gás do mundo, a China precisa garantir a sua segurança energética no transporte desses elementos. O Departamento de Energia dos Estados Unidos estimou que, em 2011, 4,5 trilhões de barris de petróleo e 0,6 trilhões de pés cúbicos de gás natural liquefeito foram transportados ao longo de todo o Mar do Sul da China por dia. Este número tende a crescer na medida em que o país tem se consolidado como uma das maiores potências econômicas do mundo (Anh 2015; Thuy; Trang 2015).

Tamanha importância estratégica revela o forte interesse de todos os países banhados pelo MSC no que concerne às questões de segurança. Exemplos históricos não faltam: (1) durante a Guerra Fria, quando algumas nações litorâneas enfrentaram ameaças militares; (2) em 1856 quando o Vietnã enfrentou ameaças e ataques em sua costa pela França; (3) em 1964 quando os Estados Unidos desferiram ataques aéreos contra o Vietnã; e (4) quando o Japão conquistou a Malaya (atuais Malásia e Brunei) durante a Segunda Guerra Mundial.

O interesse norte-americano não é novo na região. Mesmo antes, durante e após a Segunda Guerra Mundial o país tem disputado influência regional com a China. Seu forte interesse é representado pelas diversas bases militares no Sudeste, Leste e Nordeste Asiáticos, mantidas em parceria com aliados históricos e estratégicos, como Coréia do Sul e Japão (Grygiel; Mitchell 2016). ${ }^{2}$ Por um lado, a disputa revela tanto a tensão entre uma China em franca ascensão, prestes a exercer uma maior influência em toda Ásia, quanto os Estados Unidos dispostos a manter seu status quo e preservar sua forte presença em uma região de crescente e notória importância estratégica (Talmon; Jia 2014).

A China alega ser o MSC uma zona histórica de sua influência, e sob a qual ela goza de plena soberania. Tendo o controle sobre toda a região, ela seria capaz de monitorar os movimentos de navios ou qualquer outra movimentação que julgue ameaçadora contra sua soberania territorial. Anh (2015) ainda ressalta que o fato de as Ilhas Spratly estarem no meio do Mar, ofereceriam o local ideal para monitorar toda movimentação marítima em seu entorno, impedindo com antecedência qualquer ação bélica ou avessa aos seus propósitos, ou ainda a todo continente asiático. Tendo 
o domínio estratégico, a China ainda teria uma grande área para exercer seu poder naval e demonstrar sua força, operando submarinos capazes de proteger contra qualquer ameaça antes mesmo que ela chegue na costa dos países que compõem todo o Sul e Sudeste Asiático, incluindo possíveis ataques dos Estados Unidos.

A importância geoestratégica do Mar do Sul da China tem transformado o que seria uma disputa regional em internacional. Progressivamente tem se tornado um tabuleiro de xadrez estratégico para as grandes potências, seja em questões econômicas, uma vez que mais da metade da frota petrolífera e comercial do mundo passam por suas águas; mas também, e essencialmente, por questões geoestratégicas. Como afirma Huang e Jagtiani (2015, 7, tradução nossa): "Quem controla o Mar do Sul da China controla o Pacífico Ocidental”. ${ }^{3}$

\section{REIVINDICAÇÕES DOS PAÍSES BANHADOS PELO MAR DO SUL DA CHINA}

Nos subtópicos a seguir, sintetizo os principais argumentos e reivindicações dos países que reivindicam porções territoriais no Mar do Sul da China. A análise serve para mostrar como os interesses de cada país se sobressaem em seus argumentos e locais reivindicados. A síntese obedece à seguinte ordem analítica: Brunei; Camboja; República Popular da China; Indonésia; Malásia; Filipinas; Taiwan; Tailândia; e Vietnã. ${ }^{4}$

\section{Brunei}

Na parte Sul do Mar da China Meridional, Brunei reclama uma Zona Econômica Exclusiva (ZEE) de 200 milhas náuticas ${ }^{5}$ e o aumento natural de sua plataforma continental. Além disso, reivindica soberania sobre o Recife de Louisa no arquipélago das Ilhas Spratly. Desde 1982, com a Convenção das Nações Unidas sobre o Direito do Mar (CNUDM), Brunei sustenta sua suposta ZEE e a plataforma continental no Mar do Sul da China. No caso do Recife de Louisa, o país se baseia no fato de que o Recife está localizado dentro da plataforma continental reivindicada, o que naturalmente outorga seu direito sobre ele.

\section{Camboja}

O Camboja reivindica soberania sobre as ilhas, ilhotas e recifes presentes no Golfo da Tailândia, e o controle de todos esses recursos. O país também reivindica 200 milhas náuticas e o prolongamento de seu território 
continental no Golfo da Tailândia, ao longo de sua costa até o Sudoeste e Sul tailandês. Desde a década de 1960 o país reivindica essa porção territorial, provocando crises diplomáticas com o seu vizinho regional.

\section{República Popular da China}

A China, juntamente com Taiwan, possui as mais amplas reivindicações sobre o Mar do Sul da China. O país reclama soberania sobre todas as Ilhas Paracel, Spratly e Prata. Além disso, a China reivindica as principais zonas marítimas do MSC, chamadas "águas históricas" em uma área em forma de U para o Sul e Leste da costa vietnamita, alcançando o Nordeste das Ilhas Natuna controladas pela Indonésia, o Norte da Malásia, o Nordeste da costa de Brunei e o estado malaio de Sabah, e mais ao Norte tomando toda parte Oeste das Filipinas. A China também reclama uma ZEE de 200 milhas náuticas e o prolongamento de sua plataforma continental ao longo do Golfo de Tonkin.

É importante destacar que, desde 1956, a China iniciou o controle do arquipélago de Paracel, tendo total domínio em 1974. Já no arquipélago de Spratly iniciou sua ocupação em 1988. Desde então, continua a expandir o controle sobre as ilhas e recifes do arquipélago. A estimativa é que ela controle ao menos dez ilhas, ilhotas e recifes nas Spratly. Já as Ilhas Prata são controladas por Taiwan. As reclamações chinesas são baseadas em registros e mapas históricos que são usados para sustentar dois tipos de reivindicações: (1) que a China descobriu os grupos de ilhas no MSC, e (2) que eles realizaram não apenas o descobrimento, mas a ocupação e desenvolvimento do local.

\section{Indonésia}

A Indonésia controla as Ilhas Anambas, Badas, Natuna e Tambelan. O país, no entanto, reivindica uma ZEE de 200 milhas náuticas e o prolongamento de sua plataforma continental até o Sul da China, passando pelo norte das Ilhas Anambas e leste das Ilhas Natuna. Por possuir um território bastante recortado e arquipélago, suas reivindicações seguem a norma de medição contínua de suas ilhas. As ZEE e a extensão de sua plataforma continental são medidas pela continuidade de suas ilhas até que circunde todo o território aclamado pelo país. A reivindicação indonésia parte do pressuposto de que as ilhas são parte do arquipélago indonésio, uma extensão dele, e, portanto, pertencentes ao país. 


\section{Malásia}

A Malásia reivindica soberania territorial sobre a parte sul do arquipélago Spratly, além de uma ZEE de 200 milhas náuticas e o prolongamento de sua plataforma continental no MSC ao longo da sua costa Leste e da costa de seus estados Sabah e Sarawak. Além disso, reclama o prolongamento de sua plataforma até o Golfo da Tailândia além de sua costa Nordeste peninsular. Essas reinvindicações existem desde a década de 1960. Atualmente controla pelo menos três ilhas e recifes no arquipélago de Spratly. Desde 1983, quando tomou o controle do Recife de Swallow, a Malásia vem expandindo seu controle sobre a região.

\section{Filipinas}

As Filipinas reivindicam soberania sobre quase todas as ilhas do arquipélago de Spratly, com exceção da própria Ilha de Spratly em si e os Recifes Royal Charlotte, Swallow e Louisa. Também reclama uma ZEE de 200 milhas náuticas e o prolongamento de sua plataforma continental no Mar do Sul da China, especificamente a parte Oeste do país. Atualmente as Filipinas controlam oito ilhas, ilhotas e recifes ao longo do arquipélago de Spratly. $\mathrm{O}$ controle de cinco ilhas, ilhotas e recifes teve início na década de 1970, e desde então o país tem expandido seu controle sobre demais regiões. Por ser um Estado arquipélago, com território recortado, sua reivindicação segue os mesmos interesses e argumentos indonésios.

\section{Taiwan}

Taiwan, pela sua proximidade com a China, possui as mesmas reivindicações de sua vizinha. Entre as ilhas do MSC, Taiwan reivindica soberania sobre as ilhas Paracel e Spratly, além das Ilhas Prata. Taiwan também reclama as principais partes das zonas marítimas da China, em especial as chamadas "águas históricas" que se estendem tanto ao Sul quanto a Leste e Nordeste da Indonésia, passando pelo Norte da Malásia no estado de Sarawak, pelo Nordeste ao longo da costa de Brunei e o Estado malaio de Sabah, chegando ao Norte e Oeste das Filipinas. Além disso, o país reivindica uma ZEE de 200 milhas náuticas e o prolongamento natural da sua plataforma continental no Golfo do Tonkin.

Atualmente Taiwan controla Itu Aban no arquipélago de Spratly e as Ilhas Prata. O país não controla, além dessas, nenhuma outra ilha ou recife, que são dominados basicamente pelo seu vizinho chinês. Assim como a China, suas reivindicações são baseadas em mapas que são usados para 
defender suas posições de presença histórica e consequente direito natural sobre as ilhas e recifes ao seu redor.

\section{Tailândia}

A Tailândia reivindica a soberania sobre todas as ilhas, ilhotas e recifes no Golfo da Tailândia, e controla a maior parte desses recursos atualmente. O país também reclama uma ZEE de 200 milhas náuticas e o prolongamento natural de sua plataforma continental do Golfo da Tailândia que se estende ao Norte e Oeste do Golfo. Sua alegação histórica, datada desde 1959, tem ganho força desde o início da década de 1970.

\section{Vietnã}

O Vietnã reivindica a soberania sobre a totalidade dos arquipélagos de Paracel e Spratly, além de uma ZEE de 200 milhas náuticas e o prolongamento natural da sua plataforma continental no Mar do Sul da China para o Leste e Sudeste da costa vietnamita e o Golfo de Tonkin. O país também tem reivindicações de soberania para as ilhas, ilhotas e recifes até $200 \mathrm{mi}-$ lhas náuticas de seu território. Atualmente o país controla mais de 20 ilhas, ilhotas e recifes ao longo de todo arquipélago Spratly.

Seu controle sobre os recursos do arquipélago tem sido gradualmente expandido desde a década de 1970. Todavia, nenhuma ilha ou recife das Ilhas Paracel são controladas pelo país, que estão em posse da China. O Vietnã ainda controla as ilhas, ilhotas e recifes no Golfo da Tailândia. Assim como a China e Taiwan, o Vietnã alega registros históricos que remontam o período pré-colonial e colonial francês.

O breve panorama das reivindicações nos conduzem a um ambiente difícil e de contestações que vão desde alegações históricas até interesses estratégicos. $\mathrm{O}$ fato é que as disputas têm gerado incerteza sobre a estabilidade regional. Uma China cada vez mais desejosa de poder econômico e militar, ao passo que as demais nações temem ver sua pouca influência ser ainda mais minada pelo gigante chinês. O Mapa 2 resume os pontos discutidos e destaca as áreas reivindicadas por pelo menos seis países. As linhas e suas respectivas cores indicam as áreas reivindicadas por cada país. Destaque especial deve ser feito para a China, que reclama uma média de 90 por cento de todo MSC, bem como o Vietnã. 


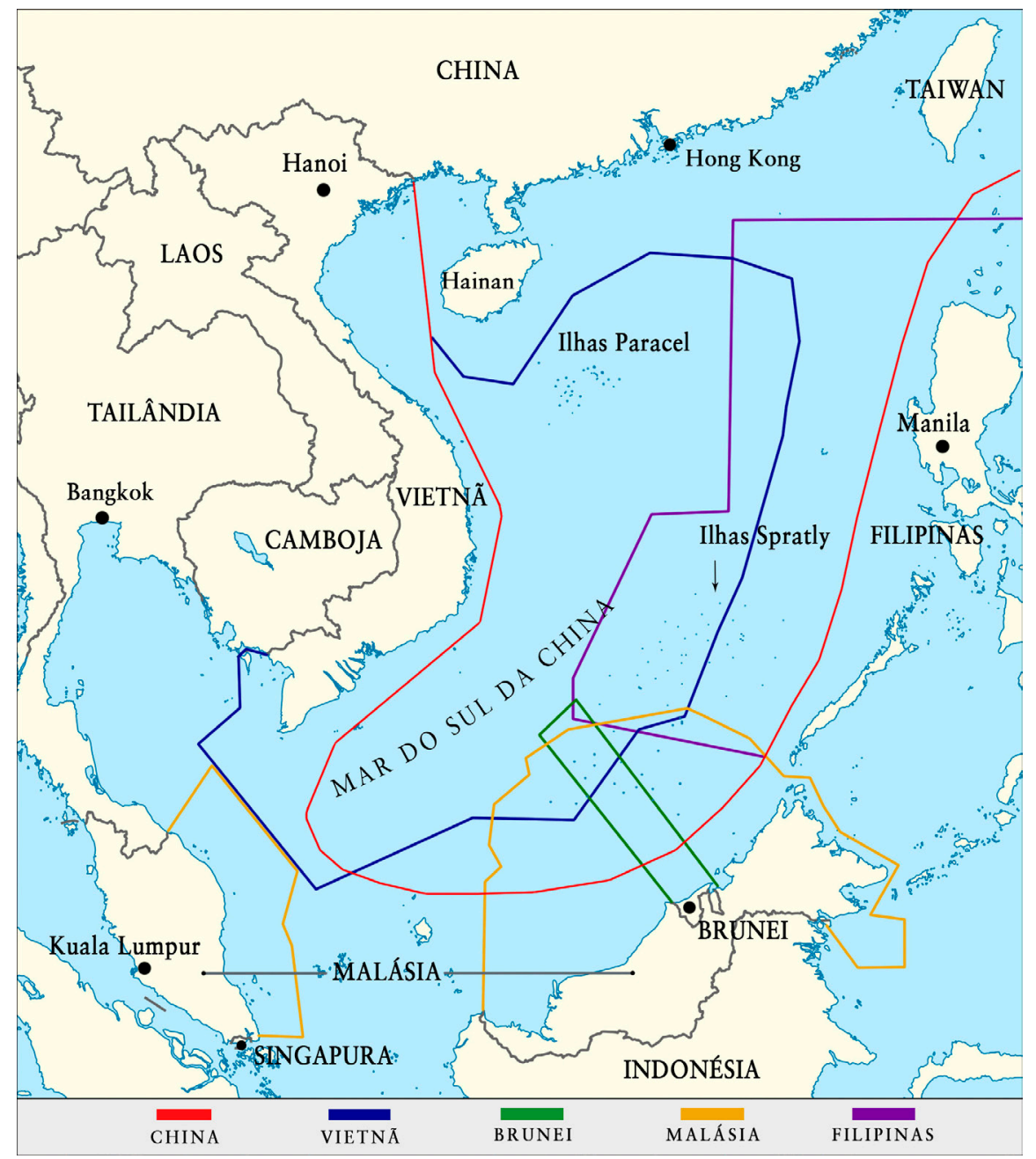

Mapa 2 - Reivindicações territoriais no Mar do Sul da China. Fonte: Elaboração própria.

\section{A RELAÇÃO CHINA-EUA E A CONTESTAÇÃO PELA SUPREMACIA NO MSC}

As tensões no Mar do Sul da China têm crescido devido a uma junção de recursos e competição geopolítica em nível internacional, misturadas com um sentimento nacionalista que une elementos históricos e contestação de soberania territorial (Hui-Yi 2016). Tais atritos são complexos 
e perigosos, e não dão sinais de que serão resolvidos em breve. Ao contrário, estão tomando uma direção cada vez mais desfavorável para a paz regional e mundial. No entanto, Cronin (2015) ressalta que tanto China quanto Estados Unidos poderiam ajudar a dirimir qualquer possibilidade de conflito. A cooperação entre as duas potências seria capaz de manter a estabilidade e reforçar o potencial da região para o comércio internacional e combate à pirataria. Não é isso, todavia, o que tem ocorrido. Mais do que o conflito regional, com diversos países reclamando vultosas porções de terra ao longo de todo MSC, é do outro lado do Pacífico onde a crise pelo controle estratégico da região tem se mostrado mais acirrado. Embora alguns analistas apontem para o aumento e possibilidade do conflito direto na medida em que a disputa por supremacia na região cresce, outros entendem que seria inviável um conflito, pois os custos pela guerra seriam altos e as incertezas provocadas seriam capazes de mergulhar a economia mundial em uma crise sem precedentes (Jayakimar; Koh; Beckman 2014; Kim 2016).

\section{"A Guerra Improvável"}

Na medida em que a China desponta como a segunda maior economia do mundo e investe pesado em seu poder bélico, torna-se um foco natural de atenção por parte dos Estados Unidos. Tal atenção se torna ainda mais relevante com as disputas territoriais no MSC pela importância estratégica da região, já discutida no início deste artigo. Os Estados Unidos e a China enfrentam hoje um dilema pelo poder de influência no mundo, de modo que a relação entre ambos é claramente tensa. Enquanto a China vê os Estados Unidos como a maior ameaça externa à sua influência regional, os norte-americanos enxergam a China como a maior ameaça ao seu status quo, podendo tomar seu lugar em diversas áreas até então hegemônicas e controladas pelos EUA. Pode a crescente tensão entre os dois nos conduzir a um próximo conflito? Para alguns estudiosos a resposta é não.

Christopher Coker, em seu recente e provocador livro The Improbable War, publicado em 2015, levanta essa discussão de grande interesse e importância geopolítica. Seu argumento é simples: um conflito entre os dois países não é inevitável, mas também não é tão fácil de ocorrer como alguns especialistas sugerem. De todo modo, como qualquer conflito teria um grave impacto sobre outras nações e todo sistema internacional, vale a pena considerar a possibilidade deste, mesmo sendo inevitável ou improvável. O autor expõe o fato de que a rivalidade entre EUA-China teria sido iniciada pelo declínio hegemônico dos EUA e o crescente poder da China, embora ainda não esteja claro se Washington irá ceder a sua posição dominante 
de forma voluntária para a China, uma vez que ambos possuem valores bastante díspares em questões como democracia e livre mercado. Essa falta de conexão seria suficiente para gerar um ambiente de desconfiança entre as duas potências e impedir qualquer incentivo real por parte dos Estados Unidos para uma suave transição de poder.

Ao longo de toda sua pesquisa, Coker (2015) prossegue identificando potenciais fontes de conflito que poderiam provocar uma guerra entre as duas grandes potências. $\mathrm{O}$ autor argumenta que o principal fator motriz por trás de qualquer potencial foco nas hostilidades será a percepção de que os governos de Pequim e Washington têm das intenções um do outro. $\mathrm{O}$ forte e crescente nacionalismo chinês, reforçado pela narrativa de humilhação que o país sofreu em tratados desiguais impostos após a derrota da China na Guerra do Ópio também é fundamental, uma vez que poderia empurrar a China em um conflito com os aliados dos EUA, ou mesmo contra a própria potência norte-americana.

Outro possível motor para a guerra seria a estratégia inconsistente dos EUA. Enquanto durante os governos de George W. Bush entre 2001 e 2009 a China foi considerada um perigo para a segurança dos Estados Unidos, a crise de 2008 mudou essa percepção, e a China tornou-se uma parte importante para a saída da crise e "aliada” dos EUA. Já a posição do governo Obama tem sido defensiva contra as investidas do gigante asiático, sem esclarecer como será a relação entre eles (Fels; Vu 2016; Friedberg 2011). Esta incerteza sobre como lidar com o crescimento da China, nas palavras do autor, tem deixado os Estados Unidos "nervoso sobre o que isto prenuncia tanto para a segurança regional quanto para a sua própria primazia no Pacífico Ocidental”' (Coker 2015, 107, tradução nossa).

No caso específico do Mar do Sul da China, a tensão entre as duas potências não se resume a questões econômicas ou estratégicas. Enquanto a China tem claramente reivindicado quase a totalidade da região e aumentado sua presença militar, os interesses dos EUA são mais complexos. Em suma, pelo menos quatro são os desafios e interesses norte-americanos na região.

O primeiro desafio está diretamente relacionado aos interesses dos EUA, que é a estabilidade da região. A estabilidade defendida foca, principalmente, em defender a liberdade de navegação, ao mesmo tempo que se mantém "neutro" nas disputas de soberania entre os países asiáticos. O comportamento agressivo da China desde 2012, no entanto, tem indicado que esse objetivo ainda está longe de ser alcançado a curto prazo. Um pleno domínio marítimo da China no MSC, local onde pelo menos metade da frota comercial do mundo circula, representaria um duro golpe contra os interesses norte-americanos e de seus aliados na região, como 
a Coreia do Sul e o Japão, além de forçar uma diminuição da sua presença militar. O segundo desafio diz respeito ao desejo dos EUA em manter sua hegemonia na região Ásia-Pacífico. No entanto, com problemas econômicos domésticos, como o alto nível de dívida pública e privada, além de alguns cortes no orçamento de defesa (que mesmo assim continua sendo, de longe, o maior do mundo), e com as caras operações militares no Iraque e Afeganistão, Washington reconhece que uma presença militar forte requer um alto gasto com defesa, capaz de impor seus interesses e dirimir os avanços chineses na região. Em terceiro lugar, os EUA precisam encontrar o equilíbrio entre apoiar seus aliados que estão, direta ou indiretamente, sendo afetados pela ascensão chinesa, sem, contudo, danificar ou atrapalhar seu relacionamento com a própria China. Por fim, a América precisa manter o ordenamento internacional respeitando a liberdade de navegação. A China tem buscado restringir a circulação de navios, o que coloca em cheque a liberdade, e, consequentemente, seus interesses no MSC (Fels; Vu 2016).

Embora o cenário entre os dois países continue incerto, o fato é que a China tem desafiado a influência dos EUA. Na África, as empresas chinesas têm investido pesadamente em países com grandes reservas minerais e recursos naturais, como Nigéria e Sudão. Enquanto os EUA consideram o respeito pela democracia e os direitos humanos como um pré-requisito básico para a cooperação econômica com os regimes autoritários, a China investe sem levar em conta essas questões. No entanto, a expansão chinesa tem sido não só no continente africano. Até mesmo na União Europeia, aliado histórico dos EUA, a China ofereceu empréstimos a países com problemas financeiros em melhores condições do que o Fundo Monetário Internacional (FMI) e o Banco Mundial, ao passo que o Reino Unido, fiel e histórico aliado de Washington, tem usado e encorajado outras nações a também tomar empréstimos de bancos chineses (Coker 2015).

\section{CONCLUSÃO}

“[...] war is a dangerous place." (Bush, 2003)

O Mar do Sul da China é um dos maiores oceanos semifechados do mundo. Sua localização geoestratégica e recursos são fatores que, em conjunto, tornam a região de interesse estratégico vital para os Estados litorâneos do Sul e Leste Asiático, mas também para os interesses dos Estados Unidos. A breve discussão apresentada neste artigo revelou a complexidade das questões que envolvem as disputas territoriais no MSC e seus possí- 
veis impactos, na medida em que os problemas não sejam solucionados com rapidez. O desenvolvimento do Direito Internacional Marítimo como importante mediador das reivindicações de disputas territoriais tem gerado cada vez mais pedidos por parte dos países solicitantes, indefinindo ainda mais a disputa. Fatores domésticos da China, questões históricas levantadas pelos países asiáticos, riqueza de recursos naturais e possíveis recursos minerais, além da crescente disputa por influência entre os Estados Unidos e a China, sem esquecer dos interesses japoneses e sul-coreanos revela a complexidade da disputa, tornando o Mar do Sul da China uma das disputas territoriais marítimas mais complicadas e difíceis em suas negociações e soluções de contendas jurídicas.

\section{REFERÊNCIAS}

Anh, N. T. L. 2015. Origins of the South China Sea Dispute. In: Huang, J., Billo, A. (Ed.). Territorial Disputes in the South China Sea Navigating Rough Waters. New York: Palgrave Macmillan. Cap. 1, 15-38.

Bateman, S., Emmers, R. 2009. Introduction: the South China Sea: towards a cooperative management regime. In: Bateman, S., Emmers, R. (Ed.). Security and international politics in the South China Sea: towards a cooperative management regime. New York: Routledge. Introduction, 1-4.

Bateman, S. 2009. Good order at sea in the South China Sea. In: Shicun, W., Zou, K. (Ed.). Maritime security in the South China Sea: regional implications and international cooperation. Surrey: Ashgate. Cap. 2, 15-34.

Bush, G. W. 2003. President removes Iraq sanctions. Washington, 7 maio. Disponível em: https://georgewbush-whitehouse.archives.gov/news/releases/2003/05/ 20030507-15.html. Acesso em: 18 out. 2016.

Buszynski, L., Roberts, C. B. (Ed.). 2014. The South China Sea Maritime Dispute: Political, Legal and Regional Perspectives. New York: Routledge.

Cáceres, S. B. 2014. China's strategic interests in the South China Sea: power and resources. New York: Routledge.

Coker, C. 2015. The Improbable War: China, the United States and the Logic of Great Power Conflict. Oxford: Oxford University Press.

Cronin, P. M. 2015. The United States, China, and Cooperation in the South China Sea. In: Huang, J., Billo, A. Territorial Disputes in the South China Sea: Navigating Rough Waters. New York: Palgrave Macmillan. Cap. 8, 149-165. 
Djalal, H. 1998. South China Sea Island Disputes. In: Nordquist, M. H., Moore, J. N. (Ed.). Security Flashpoints: Oil, Islands, Sea Access and Military Confrontation. Boston: Martinus Nijhoff Publishers, 109-133.

Dupont, A. 1998. The Environment and Security in Pacific Asia. Oxford: Oxford University Press.

Elleman, B. A., Kotkin, S., Schofeld, C. (Ed.). 2013. Beijing's power and China's borders: twenty neighbors in Asia. New York: M. E. Sharpe.

Fels, E., Vu, T.-M. (Ed.). 2016. Power Politics in Asia's Contested Waters: Territorial Disputes in the South China Sea. New York: Springer Publishing.

Friedberg, A. L. 2011 . A contest for supremacy: China, America, and the struggle for mastery in Asia. New York: W. W. Norton \& Company, Inc.

Grygiel, J. J., Mitchell, A. W. 2016. The Unquiet Frontier: rising rivals, vulnerable allies, and the crisis of American power. Princeton: Princeton University Press.

Hayton, B. 2014. The South China Sea: the struggle for power in Asia. Yale: Yale University Press.

Hong, N. 2012. UNCLOS and Ocean Dispute Settlement: law and politics in the South China Sea. New York: Routledge.

Huang, J., Jagtiani, S. 2015. Introduction: Unknotting Tangled Lines in the South China Sea Dispute. In: Huang, J., Billo, A. (Ed.). Territorial Disputes in the South China Sea: Navigating Rough Waters. New York: Palgrave Macmillan. Introduction, 1-14.

Hui-Yi, K. T. 2016. Re-contemplating the South China Sea Issue: Sailing with the Wind of the 21st Century Maritime Silk Road. The Chinese Journal of Global Governance, 2 (1), 63-95.

Jayakimar, S., Koh, T., Beckman, R. (Ed.). 2014. The South China Sea Disputes and Law of the Sea. Cheltenham: Edwar Elgar Publishing.

Jun, Q. 2015. The CLCS Modalities for Handling Submissions Involving Disputes and Their Possible Application to the South China Sea. Chinese Journal of International Law, 14 (1), 135-149.

Kaplan, R. D. 2014. Asia's Cauldron: the South China Sea and the end of a stable Pacific. New York: Random House. 
Kim, J. 2015. Territorial Disputes in the South China Sea: Implications for Security in Asia and Beyond. Strategic Studies Quarterly, summer, 107-141.

. 2016. Possible Future of the Contest in the South China Sea. The Chinese Journal of International Politics, 9 (1), 27-57.

Jacques, M. 2009. When China rules the world: the end of the western world and the birth of a new global order. New York: Penguin Press.

Kivimäki, T. 2002. War or peace in the South China Sea? Copenhagen: Nias Press.

Næss, T. 2002. Dangers to the Environment. In: Kivimäki, T. (Ed.). War or Peace in the South China Sea? Copenhagen: Nias Press. Cap. 4, 43-53.

Li, R. 2009. A rising China and security in East Asia: identity construction and security discourse. New York: Routledge.

Lo, C.-K. 1989. China's policy towards territorial disputes: the case of the South China Sea Islands. New York: Routledge.

Rosenberg, D. 2010. Governing the South China Sea: from freedom of the seas to ocean enclosure movements. Harvard Asia Quarterly, 12 (3 e 4), 4-12.

Shambaugh, D. 2005. Power Shift: China and Asia's New Dynamics. Berkeley: University of California Press.

Shicun, W. 2013. Solving Disputes for Regional Cooperation and Development in the South China Sea: A Chinese perspective. Oxford: Chandos Publishing.

Swaine, M. D. 1998. The Role of the Chinese Military in National Security Policymaking. California: RAND Corporation.

Schofield, C. 2009. Dangerous ground: a geopolitical overview of the South China Sea. In: Bateman, S., Emmers, R. (Ed.). Security and international politics in the South China Sea: towards a cooperative management regime. New York: Routledge. Cap. $1,7-25$.

Talmon, S., Jia, B. B. 2014. The South China Sea Arbitration: A Chinese Perspective. Oxford: Hart Publishing.

Thuy, T. T., Trang, L. T. (Ed.). 2015. Power, Law, and Maritime Order in the South China Sea. Maryland: Lexington Books.

Xinjun, Z. 2015. "Setting Aside Disputes and Pursuing Joint Development" at Crossroads in South China Sea. In: Huang, J., Billo, A. (Ed.). Territorial Disputes in 
the South China Sea: Navigating Rough Waters. New York: Palgrave Macmillan. Cap. 2, 39-53.

Yee, S. 2015. The South China Sea Arbitration: the clinical isolation and/or one-sided tendencies in the Philippines' oral arguments. Chinese Journal of International Law, 14 (3), 423-436.

Wang, G. 2004. The Fourth Rise of China: Cultural Implications. China: An International Journal, 2 (2), 311-22.

Weissmann, M. 2010. The South China Sea Conflict and Sino-ASEAN Relations: a study in conflict prevention and peace building. Asian Perspective, 34 (3), 35-69.

Wu, S., Zou, K. (Ed.). 2009. Maritime security in the South China Sea: regional implications and international cooperation. Surrey: Ashgate Publishing Limited. 


\section{NOTAS}

1. EIA, em inglês.

2. É importante destacar que o alto custo para manutenção das bases tem acirrado debates a respeito de suas reais necessidades, bem como a viabilidade de parcerias estratégicas na região. Para uma leitura completa sobre esse fenômeno, cito Grygiel e Mitchell (2016).

3. Texto original em inglês: Whoever controls the South China Sea controls the western Pacific.

4. A análise aqui sintetizada foi extraída de vários autores. Para uma leitura aprofundada, cito: Kaplan (2014), Jacques (2009), Kivimäki (2002), Cáceres (2014), Elleman, Kotkin e Schofeld (2013), Fels e Vu (2016), Li (2009), Lo (1989), Shicun (2013), Wu e Zou (2009), Jayakimar, Koh e Beckman (2014), Buszynski e Roberts (2014), Hayton (2014), Yee (2015).

5. Milha náutica é uma unidade de medida utilizada em navegação marítima e aérea, e na medição de distâncias marítimas. Cada milha náutica equivale a $1,852 \mathrm{~km}$. No caso de Brunei, o país reclama 200 milhas náuticas, que equivale, por sua vez, a $370,4 \mathrm{~km}$.

6. Texto original em inglês: nervous about what this portends for both regional security and its own primacy in the Western Pacific. 


\section{RESUMO}

Este artigo analisa o que está em jogo nas disputas territoriais no Mar do Sul da China e o motivo pelo qual é considerado estratégico para os países do Sul Asiático, além do choque de interesses e possível conflito militar entre China e Estados Unidos pelo controle da região.

Palavras-chave: Mar do Sul da China; China; Estados Unidos; Disputas Territoriais.

\section{ABSTRACT}

This article analyzes what is at stake in territorial disputes in the South China Sea and the reason why it is considered strategic for South Asian countries, besides the crash of interests and the possible military conflict between China and United States for the control of the region.

Keywords: South China Sea; China; United States; Territorial Disputes. 